\title{
Development of Augmented Reality Application for Onsite Inspection of Expressway Structures Using Microsoft HoloLens
}

\author{
Keang Ang Kouch, "Kriengsak Panuwatwanich, Pakawat Sancharoen \\ and Somporn Sahachaisaree
}

First submission: 3 May 2020; Accepted: 11 October 2020; Published: 8 December 2021

To cite this article: Keang Ang Kouch, Kriengsak Panuwatwanich, Pakawat Sancharoen and Somporn Sahachaisaree (2021). Development of augmented reality application for onsite inspection of expressway structures using Microsoft HoloLens. Journal of Construction in Developing Countries, 26(2): 87-116. https://doi.org/10.21315/jcdc2021.26.2.5.

To link to this article: https://doi.org/10.21315/jcdc2021.26.2.5

\begin{abstract}
This research introduces an augmented reality (AR)-based approach for the onsite inspection of expressway structures by developing an AR application, namely Holospector, deployed on the first generation of the Microsoft HoloLens headset. It was tested by a focus group of 10 postgraduate students, followed by three inspectors from the Expressway Authority of Thailand (EXAT), to investigate the practical applicability of the application. A questionnaire was employed as a research tool for measurement and assessment of the application and the HoloLens in this study. The results of this study indicated that the developed digital approach was satisfactory, easy to use and learn, useful, user-friendly and practical for EXAT expressway inspections; the users also intended to use it. Compared to the conventional approach, the current data communication and management could be significantly improved; this digital approach has the potential to help save resources, time and cost and increase work productivity.
\end{abstract}

Keywords: Augmented reality, Expressway structures, Microsoft HoloLens, Onsite inspection, Thailand

\section{INTRODUCTION}

Augmented reality (AR) has been conventionally known as the superimposition of digital or computer-generated content over the existing environment (Wang et al., 2013a). In other words, it is an advanced technology that allows users to merge virtual content into a real-world environment. It is an innovative technology that is more competent than other technologies in presenting possibilities. Recently, AR applications have been mature, versatile, well-developed and wellestablished.

It was observed that the architecture, engineering and construction (AEC) industry in the past had no wearable AR (Hammad et al., 2004); nevertheless, it has been effectively and potentially integrated at present. Certain sectors and industries (e.g., medical, military, travel and tourism industries; urban planning, architectural and civil engineering fields; maintenance, manufacture and gaming industries) have developed and deployed a variety of AR applications for their work. They could see various benefits in increasing their work efficiency, quality and productivity. AR was revealed to have great potential in enhancing the speed of information retrieval (Wang et al., 2014). It was demonstrated that

School of Civil Engineering and Technology, Sirindhorn International Institute of Technology, Thammasat University, Pathum Thani, THAILAND

*Corresponding author: kriengsak@siit.tu.ac.th 
students' understanding of construction assemblies could be enhanced when AR-enabled content was introduced (Bademosi, Blinn and Issa, 2019).

In Bangkok, Thailand, elevated expressways and elevated highways play a dominant role in lessening gridlock and congestion. The increased and extensive use of such urban infrastructures inevitably leads to the deterioration of its physical structures. As a result, inspection and maintenance are needed to guarantee serviceability and safety. Technically, the strength of the expressways consists of two main factors, service life and deterioration, which represent key concerns for structural inspections. The methods used for assessing any conditions of the existing expressway are known as inspections of structures. The process of assessment must be concise, precise and accurate to enhance safe conditions in the overall traffic system and user comfort. There are many bridge agencies and researchers in Thailand who have also conducted research studies on the development of bridge inspection methods and relevant approaches to evaluate bridge-condition ratings (Suksuwan and Hadikusumo, 2010).

At present, the current inspection operations of expressways in Bangkok are carried out by the Expressways Authority of Thailand (EXAT) using a paperbased approach. In practice, expressway inspectors need to access certain documents or information of inspected expressways, such as expressway history, technical drawings, previous inspection reports or history, manuals of specifications and standards for expressways and some three-dimensional (3D) models of the expressway. In this case, an AR application of a wearable AR system is a digital approach and efficient tool for EXAT inspectors to use in expressway inspection activities. In civil engineering, research has been conducted, for instance, to superimpose contextual information and maintenance data over the real views of facilities in structural inspections (Hammad et al., 2004) and to avoid buried utilities and underground components of built infrastructure (Webster et al., 1996). However, AR technology and Microsoft HoloLens are under-utilised in the construction industry, especially in highway or expressway inspections as reported by past studies (Kalantari and Rauschnabel, 2018; Lang et al., 2019). Research topics on AR using a HoloLens are increasing with a number of studies being conducted. However, they are still premature in relation to other industries. To fill this research gap, this study was conducted to introduce an AR-based approach, to aid onsite inspections of expressway structures by developing and testing a Microsoft HoloLens application. This research has three main objectives, as follows:

1. To introduce a digital AR approach for expressway structure inspections by developing an application that can be deployed on the first generation of Microsoft HoloLens.

2. To test and assess the developed application using a focus group of ten postgraduate students and three experienced EXAT inspectors.

3. To examine the applicability and assess the on-site usability and acceptability of the developed application on Microsoft HoloLens. 


\section{RESEARCH BACKGROUND}

\section{AR}

AR allows a user to perform tasks in a real-world environment while visually receiving additional computer-generated information to support the tasks at hand (Wang et al., 2013b). AR is also defined as a technology that merges the virtual and physical components in the real world, in real-time and in three dimensions (Azuma, 1997). Figure 1 demonstrates a screenshot of a hologram of a steel connection model that is projected onto the physical environment. AR's main goal is to make it easier for users to view digital information and to enhance their comfort, effectiveness, efficiency, quality and productivity. AR also aims to enhance and develop a user's perceptions and understanding, for communication with the physical environment. In contrast, virtual reality (VR) enables a user to experience a completely artificial scene or environment without the presence of the physical environment. AR technology has been utilised in various fields, including medicine, museums, military, manufacturing, 3D infrastructure visualisation, gaming, entertainment, robotics, training and education, remote collaboration, marketing, advertising, news and the AEC industry. AR provides enhanced perception to help users experience seeing, hearing, interacting and feeling their actual environments in innovative, digital and holographical ways that can benefit their daily lives. Integrated with the building information model (BIM), AR systems were also employed to fill the semantic gap between the digital models and the physical world on construction sites (Meža, Turk and Dolenc, 2014). This technology has numerous benefits but also contains certain aspects to be further improved such as spam, social rejection, security, public acceptance and interoperability (Kooper and Maclntyre, 2001; 2003).

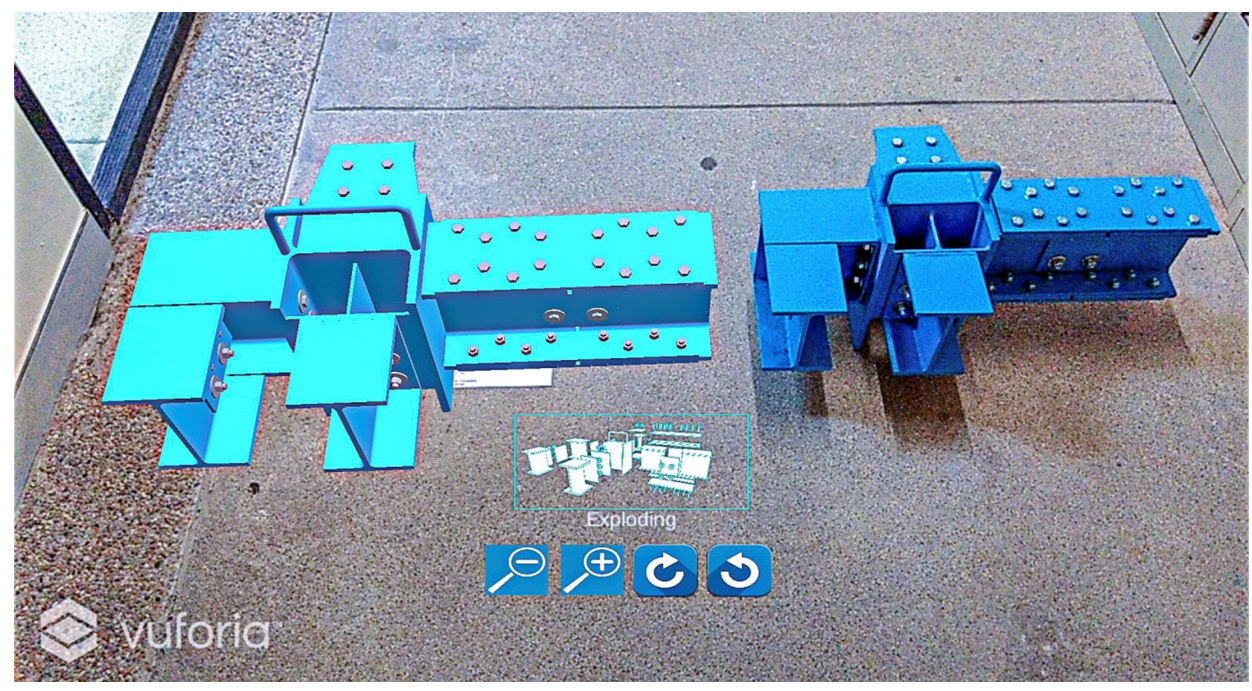

Figure 1. A hologram of a steel connection model projected onto the real environment 


\section{Overview of Microsoft HoloLens and Its Current Use Cases}

Microsoft HoloLens is designed to be a wearable computer and self-contained holographic headset, featuring a see-through, holographic display and multiple advanced sensors, allowing users to map the physical environment (Taylor, 2016). This device enables users to naturally interact with digital objects or holograms and merge them into the physical environment. They can place or fix those holograms on real-world objects or the environment and simultaneously interact with them in three ways: gestures, gaze and voice commands. For instance, in gesture tracking with the HoloLens' multiple depth perception cameras, the device is capable of precisely tracking users' hands and recognising and detecting gestures; users can point and click or air-tap, scale up or down, or use hand gestures. Without the presence of a keyboard and mouse, its main control channel is the gesture recognition module. This module is used to manipulate, operate, control and model or draw any 3D objects in the real world in a natural way. The real innovation of this wearable headset is that it combines several advanced technologies into a single, autonomous and portable device. Recently, Microsoft Hololens has been used to improve a main product's location and positionchange detection (Radkowski and Ingebrand, 2017), to conduct assembly tasks (Blankemeyer, Wiemann and Raatz, 2018), to visualise and perform sequences of programme operations in the field of robotics (Guhl et al., 2018; Rückert, Meiners and Tracht, 2018), to augment the number of component kits to be picked in the field of logistics (Hanson, Falkenström and Miettinen 2017), to conduct quality measurements of a product's assembly (Canepa-Talamas, Nassehi and Dhokia, 2017), to enhance operations of inspection and maintenance in the aviation industry (Eschen et al., 2018), to create a stereoscopic view transformed by a simulation model (Karlsson et al., 2017) and to test electrical construction layout tasks with AR (Chalhoub and Ayer, 2019).

\section{Previous Studies on Wearable AR Devices in Civil Engineering Inspection}

A wearable AR device helps and allows an onsite inspector to perform handsfree inspection tasks by superimposing the relevant information, such as technical drawings, previous inspection reports or history, manuals of specifications and standards and holograms onto the real scene. For instance, the Mobile Augmented Reality System for Infrastructure Field Tasks (MARSIFT) was developed to enhance the efficiency and safety of all workers during the process of construction, inspection, maintenance and repair in infrastructure projects (Hammad et al., 2002). Another research study was conducted to augment contextual information and maintenance data in real views of facilities in bridge inspections (Hammad et al., 2004). Furthermore, to avoid buried utilities and underground components of built infrastructure, a system was presented to demonstrate the potential of AR in assisting maintenance workers to detect existing underground utilities (Webster et al., 1996). In the field of facility management, a natural marker-based AR framework was proposed to digitally aid facility-maintenance operators in navigating to target items and conducting maintenance and repair (Koch et al., 2014). In addition to AR technology, the BIM also plays a dominant role in the development and improvement of AR applications. For instance, a locationaware AR framework was developed to be employed in facility-maintenance management to display and update the information of hidden items in real-time; 
this system helps to reduce the time of task completion by about $65 \%$ compared to the conventional approach and improves the accuracy of localisation by about $1 \mathrm{~m}$ (Chen, Li and Cheng, 2019). The researchers have also investigated the markerless BIM-based mobile AR application for onsite inspections where three different methods were used for evaluation: (1) Two-dimensional (2D) data, (2) Monocular Simultaneous Localisation and Mapping (SLAM) methods and (3) RGBD devices (Microsoft Kinect and Google Project Tango) (Kopsida and Brilakis, 2016). Another framework called BIM-based Markerless Mixed Reality (BIM3R), with the integration of Computerised Maintenance Management Systems (CMMSs), BIM and video-based tracking, was proposed to retrieve the necessary information and the user's location, display maintenance operations and make collaboration between the office and the site possible (Ammari and Hammad, 2014).

\section{RESEARCH DESIGN}

This research was undertaken in four phases. The first phase was the review of previous studies to gain background knowledge of AR and its applications in construction. This phase also involved the development of a number of $A R$ prototypes to find the necessary AR features, to create the HoloLens application, namely Holospector. In the second phase, an exploratory study was performed to gain a better understanding of EXAT's current inspection practices. These practices provided inputs for the third phase, the development of the Holospector application. The fourth phase tested the developed application, first with a group of students. This was followed by refinement and the final test with the actual EXAT inspectors, to assess the application within the actual setting. The details of these phases are presented in the following sections.

\section{Phase 1: Review of Previous Studies and AR Prototypes Development}

An extensive and critical review of the literature was conducted to compile and better understand the research that is pertinent to structural inspection, applications of information and communication technology (ICT) in highway or expressway infrastructures and the latest AR engineering applications and development. The knowledge compiled in this phase was integrated and incorporated into the development of the application in this research study.

Additionally, certain AR prototypes, namely the marker-based AR project, user interface controller, linked and clickable buttons, expressway inspection form in the AR application, construction sequence and AR keyboard were developed, deployed, tested and assessed. The capabilities of the Microsoft HoloLens and the applicability of AR applications in an onsite inspection and condition assessment activities were determined.

\section{Phase 2: Exploratory Study}

The EXAT was chosen as the subject for this research due to the ongoing research collaborations with one of the co-authors of this article and to enhance and modernise EXAT's inspection operation in response to Thailand's Industry 
4.0 movement. For this task, the research team visited EXAT's Maintenance Department (Expressway Maintenance Division) to conduct interviews. The team also explored the use of ICT in current inspection activities conducted by EXAT, which are data communication and management, actual onsite inspection activities, current inspection tools, issues and challenges and expected functionalities of AR applications. The results obtained from this exploratory study benefited the design and development of the Holospector application for expressway inspections.

\section{Overview of current expressway infrastructure inspection and maintenance}

Currently, the EXAT has been using an inspection and maintenance system derived from the Japan International Cooperation Agency (JICA) system since 1994. The inspections are divided into three classes: (1) Daily inspection, (2) Routine inspection and (3) Special inspection. Among these three types of inspection, the routine inspection was chosen and considered in this study. A routine inspection is a visual inspection ranging from a walking condition survey to using special equipment. It is routinely conducted for collecting the condition data of different structural components that are the main load-carrying components. In general, the necessary structural components that need to be routinely inspected are the concrete decks, corrugated metal decks, concrete girders, concrete intermediate diaphragms, steel plate girders, steel intermediate diaphragms, steel bracing, box girders, struts, shear keys, deviator blocks, prestressed tendon tubes, prestressed tendon support, seismic buffer, drainage system (in the box-girder structure), bearings, pedestal, cantilever deck, concrete cross beams, steel cross beams, concrete pier, steel pier, footing, retaining wall and drainage system.

The condition rating is an important task in the expressway inspection; hence, the inspector needs to determine and then choose one of the four conditions: (1) Very good, (2) Good, (3) Fair and (4) Poor. As a result, the collected data can be used and analysed for further actions. The EXAT classifies the condition rating of their expressways into four condition ratings as mentioned previously.

\section{Findings from the exploratory study}

The meetings and interviews with the EXAT staff were conducted at one of the EXAT's main offices. During a meeting with two staff members who were structural inspectors, AR technology and the Microsoft HoloLens were introduced to the staff. Certain AR prototype applications were also demonstrated. This exploratory study enabled the authors to establish a baseline understanding of current expressway operations conducted by the EXAT. Therefore, the Holospector application can be designed and developed according to the practical contexts that are specific to the EXAT. The inspection team of the EXAT consisted of two teams of four crew members (two expert inspectors and two technicians). As a standard practice, an expressway inspection was carried out four days a week and only a $2-\mathrm{km}$ inspection of expressway structures was completed daily. The expert inspectors had engineering diploma qualifications in construction and the engineers had a Bachelor of Engineering degree. 
The following challenges and issues of current expressway inspection at the EXAT were identified from the interviews:

1. Workforce limitation: In the inspection activities conducted by the EXAT, it was recommended that onsite inspection verification be crosschecked by another inspector; however, they could not do this because of limited inspectors. Additionally, if verification was needed, photos taken onsite would be used in this case.

2. Paper-based versus digital approaches: At the time of this study, a paper-based approach was commonly used in onsite inspections and condition assessment activities. The staff recognised that it was a timeconsuming and ineffective approach when onsite inspectors had to fill out many forms manually. More importantly, 40 pages of A4 paper are used daily for data collection of expressway inspections with this approach. This is not environmentally friendly. In this case, it was proposed by the research team that a digital AR approach could help EXAT to conduct the expressway inspections in a more sustainable and environmentally friendly way.

3. Data communication and management and online database: After collecting data from onsite inspections, inspectors needed to manually transfer the data from the paper forms into electronic records upon returning to the office. In fact, there was no effective data communication and management between the office and the onsite inspection team. The collected data and information were stored on a local server since there was no cloud storage and cloud database.

4. The use of ICT tools for inspections: At the EXAT, there was no technology such as AR used in the current inspection activities. Only smartphones were sometimes used to access files. Additionally, wearable devices were not present.

The listed findings led to the development of the Holospector application which would help address the challenges faced by the EXAT teams. For instance, the digital approach would help onsite inspectors collect inspection data using a Microsoft HoloLens headset in a digital and hands-free manner and the collected data would be automatically sent and stored in the online database.

\section{Phase 3: Development of the HoloSpector Application}

Following the review of past research, development of AR prototypes and exploratory study, the Holospector application was designed and developed according to the expressway inspection and condition assessment operations of EXAT's inspection works. The application was technically built using the Universal Windows Platform (UWP) and then deployed on the first generation of Microsoft HoloLens for subsequent testing and assessment. 


\section{Research tools}

A number of software tools were utilised in the development of the Holospector application, including Unity, Microsoft Visual Studio Enterprise, HoloLens emulator, Autodesk 3Ds Max, SketchUp, AutoCAD and Adobe Photoshop. Among these tools, Unity was the main platform to create the application. The main reason for using the Unity platform in this study is that Unity is a feature-rich, fully integrated development engine, providing out-of-the-box functionality for the creation of interactive 3D contents. It is a cross-platform game engine for building 2D or 3D games. It is also a complete platform that enables developers to deploy programmes across mobile devices, desktops, VR or AR devices, consoles, or the Web. In other words, it technically supports a variety of platforms and allows developers to develop a variety of applications. Unity is also recommended by Microsoft, to create HoloLens applications using the UWP.

The hardware employed for the development of the Holospector application included the first generation of Microsoft HoloLens (as shown in Figure 2) and a gaming laptop running Windows 10 Education. To enable all functionalities and interactions, C sharp (C\#) was used as the programming language in creating the Holospector application. Figure 3 presents an example of a C\# script used to send the data from the application. An example of a Unity Scene Editor for creating a hologram menu is illustrated in Figure 4.

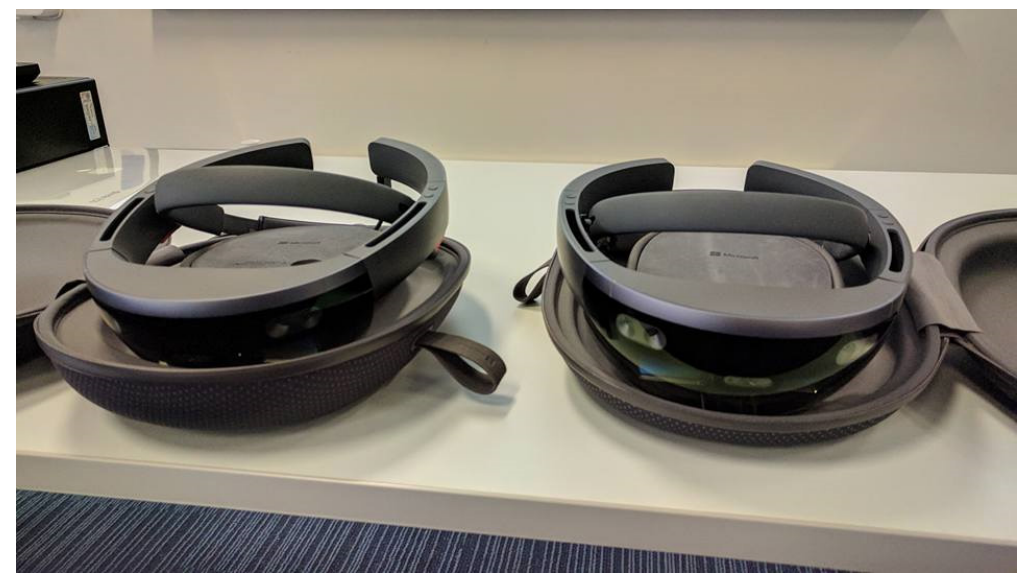

Figure 2. The first generation of Microsoft HoloLens 


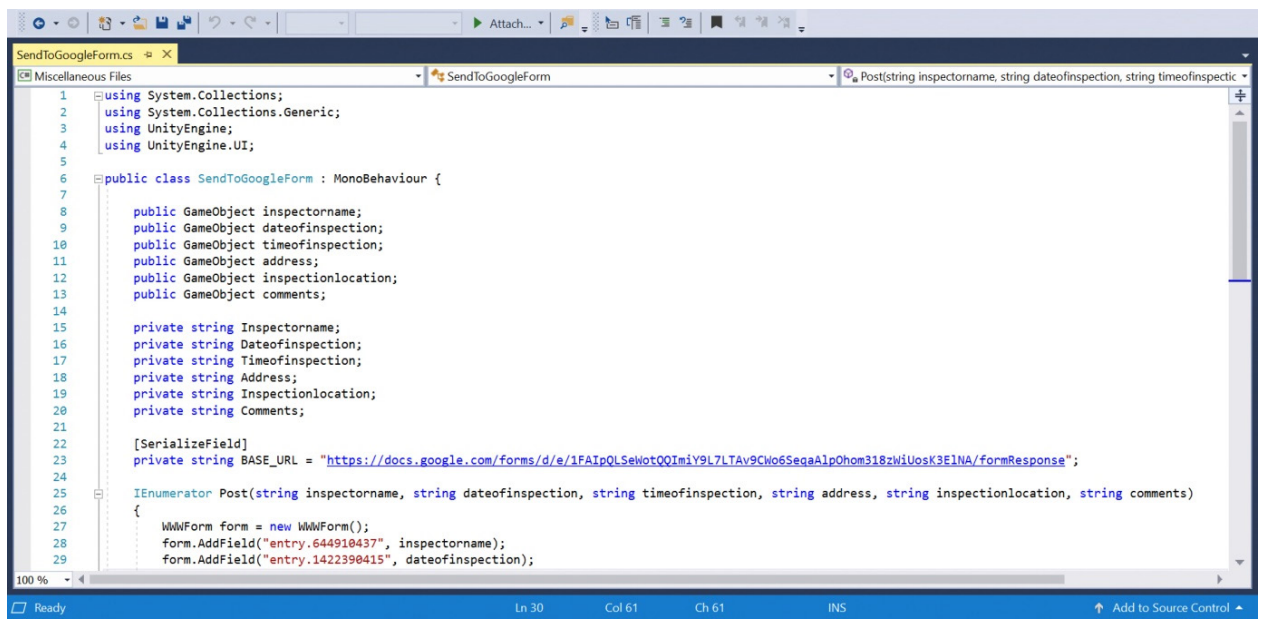

Figure 3. Example of C\# script of data export function

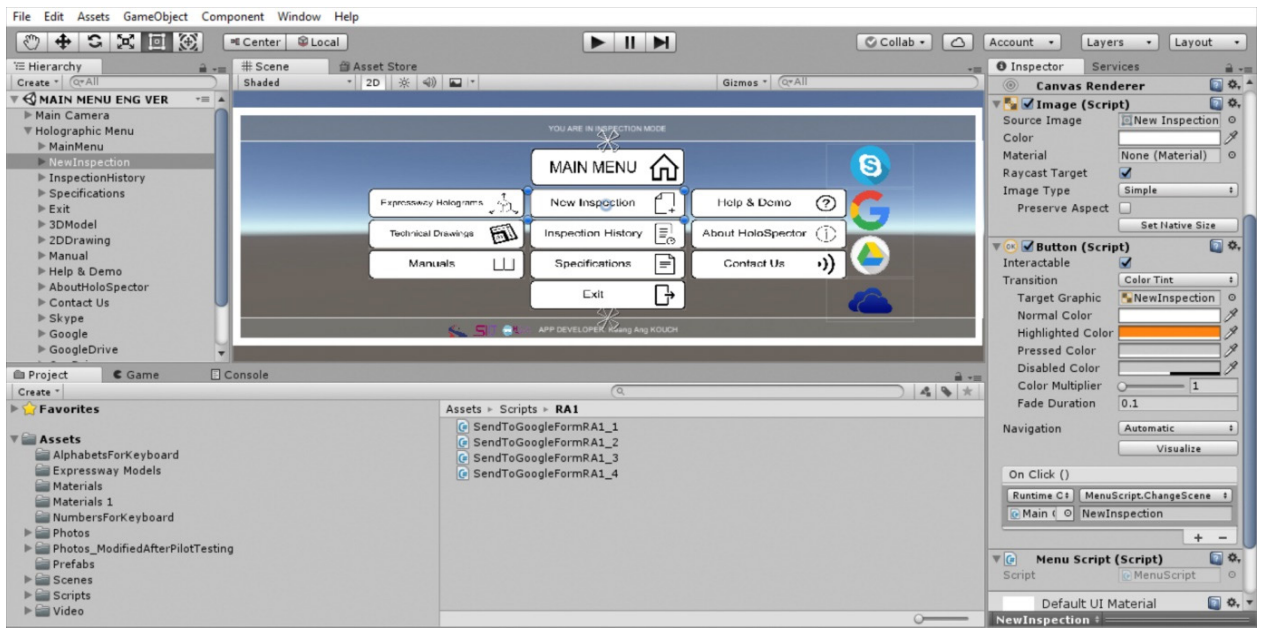

Figure 4. Screenshot of the Unity Scene Editor

\section{Development workflow of the HoloSpector application}

The development workflow of the Holospector application was based on three main elements: (1) 3D asset creation, (2) Holospector application development and (3) Holospector application compiler deployment. As presented in Figure 5, the first element provides 3D structures, contents, or holograms for the Holospector application. The second element is the designing stage for the inspection menu and interactions between the user and the application. The 
last element produces the final product of the Holospector application to be deployed on a HoloLens emulator for testing and then on the actual Microsoft HoloLens headset.

\section{D ASSET CREATION}

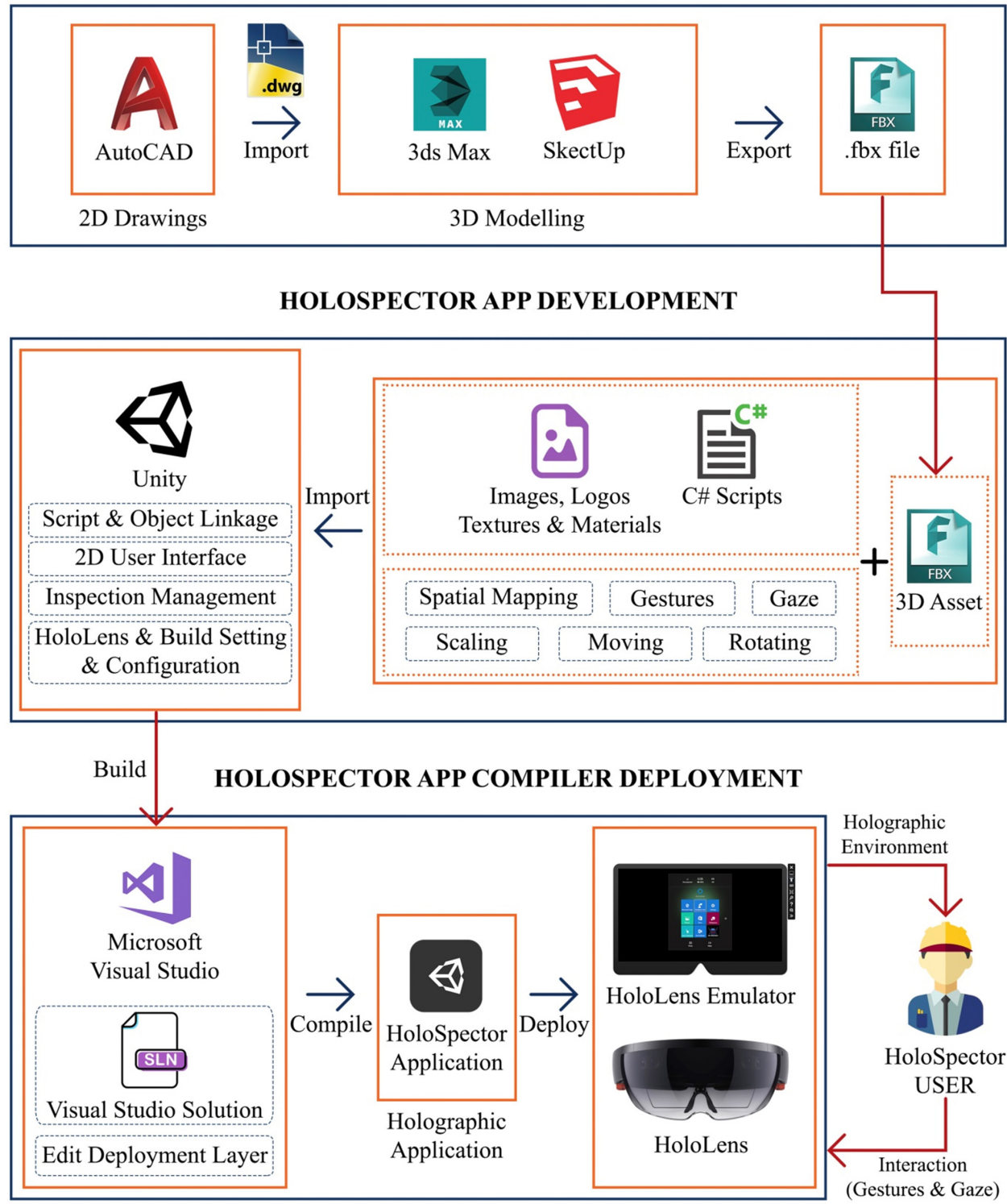

Figure 5. Development workflow of the HoloSpector application 


\section{Design considerations for the HoloSpector application}

For the Holospector application to be user-friendly, accessible, simple and visible for the users, the following design considerations were observed:

1. Design considerations for an expressway inspection environment: During an expressway inspection, onsite expressway inspectors are constantly surrounded by busy and noisy spaces or environments. Therefore, voice controls or commands, one of the three means of interactions of Microsoft HoloLens, were not considered or employed in this application development since the users would find it hard to perform the actions. Hence, only the gaze and gestures were taken into consideration; these two means of interactions allow the users to navigate and interact with all objects and components in the Holospector application.

2. Design considerations for expressway inspectors: For this wearable AR system, the end-users are expressway inspectors who are currently conducting expressway inspections and working for the EXAT.

3. Design considerations for user interface (UI) design and development for the Holospector application: Since simplicity was important in the designing process, all irrelevant or unnecessary objects and information were taken out. Only the essential elements were implemented. In developing the UI for the Holospector application, there are certain essential components to be considered, namely, text or font, button design (icon, geometry, size and colours), input controls, lighting conditions (indoor and outdoor), holographic menu screen or layout, hologram, perceived ease of use, perceived usefulness, ease of learning, attitude towards use, behavioural intention to use and satisfaction and pleasure of use.

\section{Functionalities of the HoloSpector application}

The development of the Holospector application consisted of two stages: (1) Preliminary development and (2) The refinement of the application. The preliminary development of the application was performed, based on the compiled knowledge, prototyping experiments and input from the exploratory study. The preliminary version was tested, refined and assessed in the actual inspection environment. The preliminary version had five main functions, namely, the main menu, click to read, hologram, click to input and exit. The refined version consisted of 15 main functions, namely, the Main Menu, New Inspection, Inspection History, Specifications, Expressway Hologram, Technical Drawings, Manuals, Help and Demo, About Holospector, Contact Us, Skype, Google, Google Drive, OneDrive and Exit. For the refined version, there are English and Thai versions (as sown in Figure 6), but only the Thai version was used for the testing with all EXAT inspectors, as they were all Thai and did not have a good command of English. The following sections provide the details of the testing and assessment of the Holospector application. 


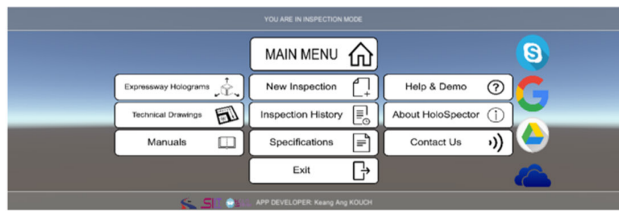

(a)

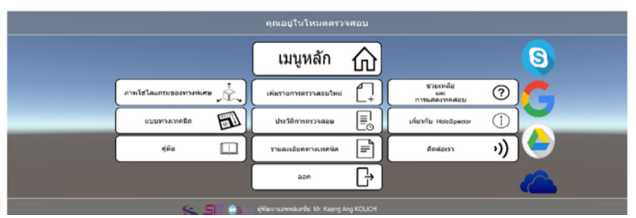

(b)

Figure 6. (a) English and (b) Thai versions of the refined version of the Holospector application

\section{Phase 4: Testing, Refinement and Final Assessment of the Application}

To successfully test, refine and assess the Holospector application, 10 postgraduate students and three EXAT inspectors were recruited to test and assess the preliminary version (developed from Phase 3) and the refined version of the application, respectively. The postgraduate students were selected to test the preliminary version of the application because it was more feasible to conduct a test in a controlled environment, to examine certain aspects of the application. All postgraduate students had civil engineering backgrounds and some knowledge of structural inspections. Testing the preliminary version of the application was focused on obtaining feedback on the basic UI of the application and basic operations of the HoloLens unit. This test resulted in the modification of the UI, which was later incorporated in the refined version of the application. The ten postgraduate students were recruited to assess the preliminary version of the application in a "focus group" manner. Therefore, the questionnaire was used as a guide to indicate feedback on the key aspects of the application, rather than to draw a statistical inference. Given the context of this research, this sample size was deemed sufficient. The refined version of the application was finally assessed by three EXAT inspectors. This final assessment of the application sought comprehensive feedback from the inspectors on the actual usage of the application within an actual onsite inspection environment. The EXAT inspection team consisted of four members. One inspector was not available to participate in the assessment exercise.

The main differences between the preliminary version and refined version are listed as follows:

1. UI: The preliminary version's results led to the final design of the UI of the refined version. The updates of button design made the buttons more visible and simpler. This benefits the visibility and interactions between the user and the application in a real-world environment.

2. Functions: The preliminary version had only five basic functions (the Main Menu, Click to Read, Hologram, Click to Input and Exit). The refined version consisted of ten more functions, mainly, adding the capability to transfer data and retrieve documents, which were completer and more suitable for EXAT inspectors to perform onsite inspections.

3. Language use: For the preliminary version, the English language was used since this version was tested and assessed by postgraduate students who are international students and are able to use English. For the refined 
version, there were English and Thai versions. However, only the Thai version was used, as the EXAT inspectors (who were Thai) did not have an adequate level of English proficiency.

\section{The HoloSpector application testing and assessment procedures}

There are four steps for postgraduate students and three steps for EXAT inspectors to complete in testing and assessing the Holospector application, as described as follows:

Step 1: Introduction to the testing and instructions.

Participants were asked to read the research background and preface, to better understand the research project they participated in. Then, they were instructed to read the instructions on how to complete the questionnaire. Confidentiality statements were provided and consent was sought from each participant before the test. Lastly, instructions on how to use the Holospector application on Microsoft HoloLens were provided, with the assistance of the first author of this paper.

Step 2: Completion of Section A (pre-test questions).

Before testing the Holospector application, the participants were requested to read and then answer the background questions. The aim of these questions was to understand the backgrounds of participants and their prior exposure to AR technology and wearable AR devices. They were asked to provide their basic information, such as gender, age, education level and their experience with AR technology.

Step 3: Testing of the HoloSpector application.

After completing Step 2, the participants were told to wear the Microsoft HoloLens and launch the Holospector application to conduct the test as below.

1. For the preliminary version, there were three main functions for the postgraduate students to test. The first is Click to Read. The second is Hologram and the third is Click to Input. All interactions with the application were performed by using the gaze and gestures. Figure 7 shows examples of the screenshots of the preliminary version of the application.

2. For the refined version, there were six main functions for the EXAT inspectors to test. These are Hologram of Expressway, Technical Drawings, Manuals, New Inspection, Inspection History and Specifications. All interactions with the application were done by using the gaze, gestures and HoloLens clicker. Figure 8 illustrates a screenshot example of the hologram menu of the refined version of the application, overlaid in the actual testing environment. 
Step 4: Completion of Section B (post-test questionnaire).

After the participants completed the test, they were then required to complete a post-test questionnaire that assessed the usability and acceptability of the Holospector application. For instance, they were asked to assess the quality and visibility of the holograms, perceived ease of use, perceived usefulness, ease of learning and comfort of the HoloLens.
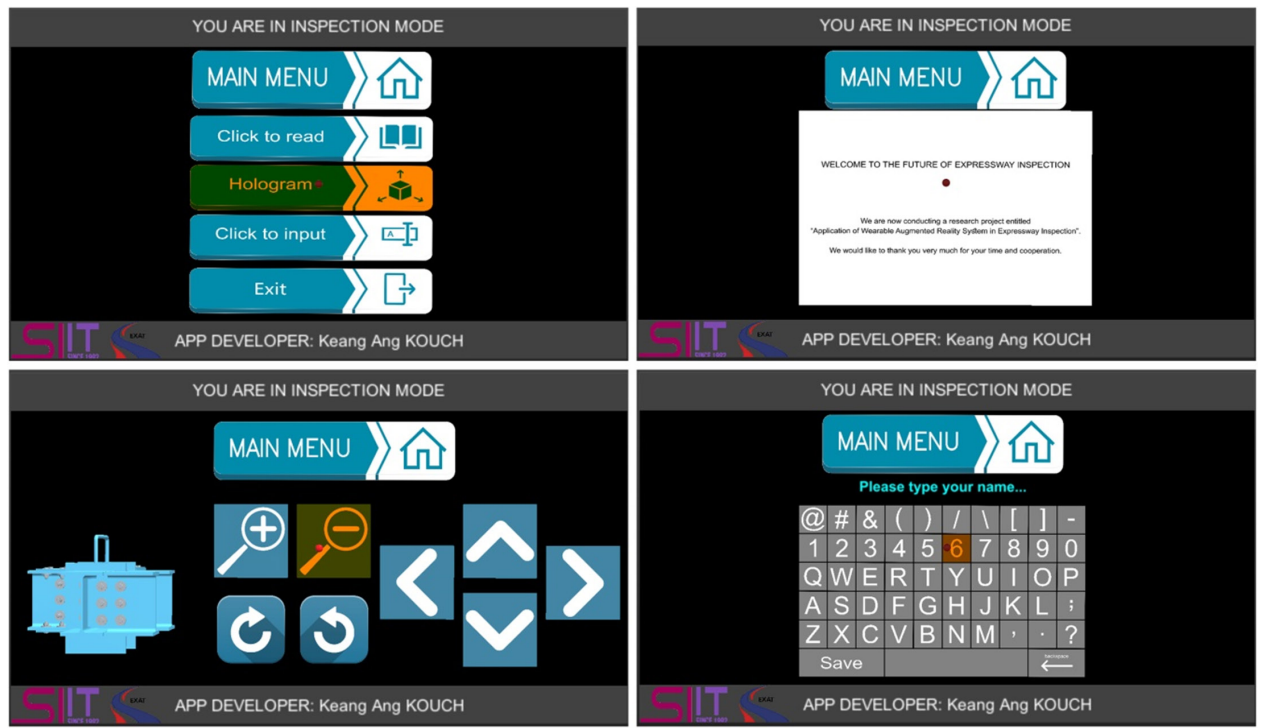

Figure 7. Screenshots of the preliminary version of the application

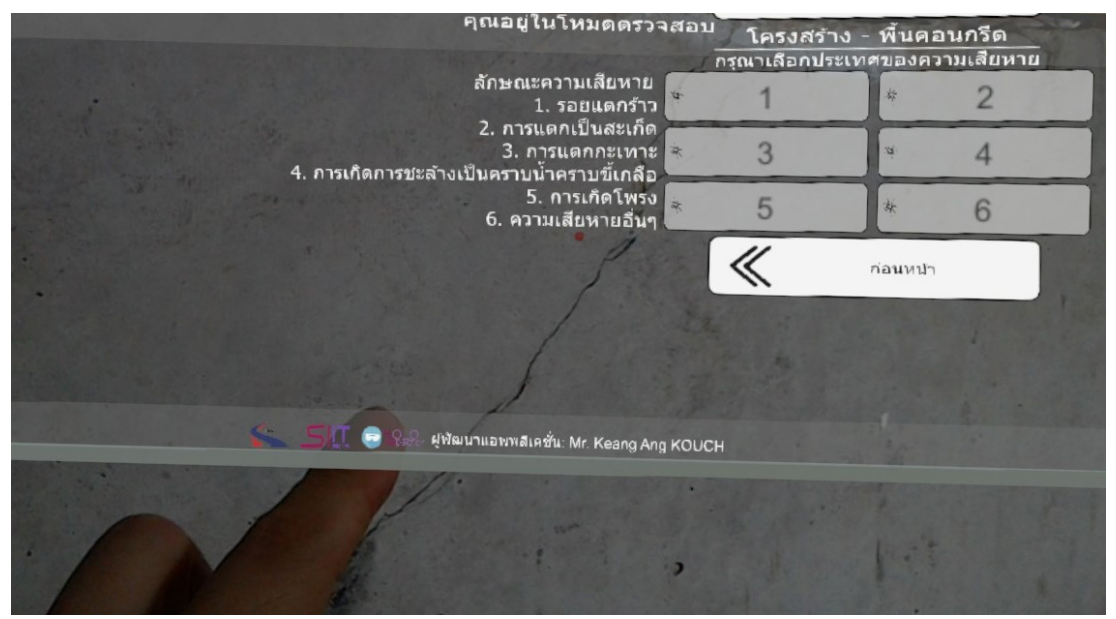

Figure 8. Screenshot of the hologram menu of the refined version (in Thai) overlaid on a concrete surface 


\section{Questionnaire design for the assessment of the application}

Questionnaires were designed to collect information on the user experience (UX) and usability of the preliminary version and refined version of the Holospector application. This information included basic interactions, perceived ease of use, perceived usefulness, ease of learning, attitude towards use, behavioural intention to use, satisfaction and pleasure, comfort, perceptions and contributions of the ten selected postgraduate students and the three selected EXAT inspectors. These questionnaires were designed by adopting the questionnaires used in previous studies of technology acceptance and adoption (Fishbein and Ajzen, 1975; Parkes, 2013; Venkatesh, Thong and Xu, 2012). There were six types of questions used in the questionnaires, namely, close-ended, fill-in-the-blank, multiple-choice, yes/no, 5-point Likert scale (ranging from "Strongly disagree", "Disagree", "Neutral", "Agree" to "Strongly agree") and open-ended questions.

The questionnaire used for the assessment of the preliminary version of the application consisted of two sections: Sections A and B, with 15 pages in total. Section $A$, the pre-test questions, consisted of three parts: (A1) Basic information of participants, (A2) AR experiences and (A3) Wearable device experiences. Section B, the post-test questionnaire, consisted of 10 parts: (B1) Testing UI components (texts, buttons and input controls), (B2) Testing holographic menu in different lighting conditions (indoor and outdoor), (B3) Holographic menu screen, (B4) Perceived ease of use, (B5) Ease of learning, (B6) Satisfaction and pleasure, (B7) Challenges in using the preliminary version, (B8) Expected improvements for the preliminary version, (B9) Perceptions towards AR and Microsoft HoloLens in an infrastructure inspection and (B10) Feedback and comments.

The questionnaire used for the assessment of the refined version of the application also consisted of two sections: Sections A and B, with 18 pages in total. Section A, the pre-test questions, consisted of three parts: (A 1) Basic information of participants, (A2) AR experiences and (A3) Wearable device experiences. Section $B$, the post-test questionnaire, consisted of 13 parts: (B1) Perceived ease of use, (B2) Perceived usefulness, (B3) Ease of learning, (B4) Attitude towards use, (B5) Behavioural intention to use, (B6) Satisfaction and pleasure, (B7) Comfort of the wearable HoloLens, (B8) Evaluation of the refined version of the Holospector application, (B9) Optimisation of the functionalities of the refined version, (B10) Challenges in using the refined version, (B11) Expected improvements, (B12) Perceptions towards AR and the refined version of the Holospector application and (B13) Feedback and comments.

\section{RESULTS AND DISCUSSION}

\section{Results from the Preliminary Version of the HoloSpector Application}

\section{Participants' demographic information}

Nine male postgraduate students and one female postgraduate student participated in the testing of the preliminary version of the application. Gender did not affect the testing results of AR technologies in past research conducted 
by Hou and Wang (2013). Therefore, gender differences in this research were not considered. The age of the postgraduate students varied from 22 years old to 29 years old. The mean value of the participant age was 25.6 years old. In terms of academic background, there were six master's students and four doctoral students. All students were completing their civil engineering degrees at the same university where the authors were located.

\section{Test durations}

The testing of the preliminary version of the application took an average of $28.2 \mathrm{~min}$ for the participants to complete the test. Among the 10 participants, the shortest testing duration was 22 min while the longest duration was 32 min.

\section{Assessment of the preliminary version of the HoloSpector application}

Out of the 10 students who participated in the testing of the preliminary version of the application, eight had prior knowledge of AR technology. Only three students had previous exposure to certain AR mobile applications. For wearable device experiences, two students have used a VR headset (HTC Vive) previously, but no students had ever used a Microsoft HoloLens. Table 1 shows the results of 5-point Likert questions on certain factors, namely, Ul components, holographic menu screen, perceived ease of use, ease of learning and satisfaction and pleasure, of the preliminary version of the Holospector application. Specific findings from these questions are highlighted as follows:

1. UI components: All participants accepted that they could clearly see and read the texts and buttons in the holographic menu. The font used in this application was Arial which is widely known as a basic font that is compatible with a variety of hand-held and wearable devices. The users prefer this font since it could reduce confusion and eye-strain when the texts are generated (Bernard et al., 2003). It was found that 9 out of 10 participants agreed or strongly agreed with the font, icons for buttons, button colour and size designed for the preliminary version. All participants agreed or strongly agreed with the button geometries and seven participants agreed or strongly agreed with the input fields.

2. Holographic menu in different lighting conditions: All participants accepted that the holographic menu of the preliminary version on Microsoft HoloLens can be seen under both environmental conditions: indoor and outdoor.

3. Holographic menu screen: All participants agreed or strongly agreed with the design of the holographic menu screen of the preliminary version.

4. Perceived ease of use of preliminary version: Nine out of ten participants agreed or strongly agreed with the acceptable loading time, terminology used, easiness and effortlessness of the preliminary version. They also believed the expert inspectors would use the Holospector application. All participants agreed or strongly agreed with the user-friendliness and they would use it if they were inspectors. 
5. Ease of learning: All participants agreed or strongly agreed that they learned to use it and became skilful quickly. The application was easy to use and remember.

6. Satisfaction and pleasure: All participants agreed or strongly agreed that they were satisfied. The application was fun and functional and they would use it if they became expressway inspectors. Eight of them agreed or strongly agreed that the application worked the way they expected and wanted it to work. Additionally, nine of them agreed or strongly agreed that the application was pleasant.

Table 1. Summary of results of 5-point Likert questions on the usability and acceptability of the preliminary version of the Holospector application

\begin{tabular}{|c|c|c|c|c|c|c|}
\hline 5-Point Likert Questions & $\begin{array}{l}\text { Strongly } \\
\text { Agree }\end{array}$ & Agree & Neutral & Disagree & $\begin{array}{l}\text { Strongly } \\
\text { Disagree }\end{array}$ & Total \\
\hline \multicolumn{7}{|l|}{ UI Components } \\
\hline $\begin{array}{l}\text { I am happy with the font } \\
\text { used in the application. }\end{array}$ & 3 & 6 & - & 1 & - & 10 \\
\hline $\begin{array}{l}\text { Icons used for buttons in the } \\
\text { application are simple and } \\
\text { easy to understand. }\end{array}$ & 6 & 3 & 1 & - & - & 10 \\
\hline $\begin{array}{l}\text { I am satisfied with the button } \\
\text { geometries in the application. }\end{array}$ & 5 & 5 & - & - & - & 10 \\
\hline $\begin{array}{l}\text { The button colour is visible } \\
\text { and pleasing. }\end{array}$ & 5 & 4 & 1 & - & - & 10 \\
\hline $\begin{array}{l}\text { The buttons are large and } \\
\text { easy to select. }\end{array}$ & 6 & 3 & 1 & - & - & 10 \\
\hline $\begin{array}{l}\text { I find it easy to enter texts } \\
\text { into the input fields. }\end{array}$ & 1 & 6 & 2 & 1 & - & 10 \\
\hline \multicolumn{7}{|l|}{ Holographic Menu Screen } \\
\hline $\begin{array}{l}\text { The menu in the application } \\
\text { is clear and intuitive with a } \\
\text { minimum amount of text. }\end{array}$ & 4 & 6 & - & - & - & 10 \\
\hline $\begin{array}{l}\text { The screen layout is efficient, } \\
\text { visually pleasing and easy } \\
\text { to understand without the } \\
\text { presence of distracting } \\
\text { components. }\end{array}$ & 4 & 6 & - & - & - & 10 \\
\hline \multicolumn{7}{|l|}{ Perceived Ease of Use } \\
\hline $\begin{array}{l}\text { The loading time of the } \\
\text { application is acceptable. }\end{array}$ & 2 & 7 & - & 1 & - & 10 \\
\hline $\begin{array}{l}\text { Terminology used in the } \\
\text { application is simple and } \\
\text { easily understood. }\end{array}$ & 5 & 4 & 1 & - & - & 10 \\
\hline
\end{tabular}


Table 1. Continued

\begin{tabular}{|c|c|c|c|c|c|c|}
\hline 5-Point Likert Questions & $\begin{array}{l}\text { Strongly } \\
\text { Agree }\end{array}$ & Agree & Neutral & Disagree & $\begin{array}{l}\text { Strongly } \\
\text { Disagree }\end{array}$ & Total \\
\hline It is simple and easy to use. & 8 & 1 & 1 & - & - & 10 \\
\hline It is user-friendly. & 5 & 5 & - & - & - & 10 \\
\hline $\begin{array}{l}\text { It is effortless and I can use it } \\
\text { without written instructions. }\end{array}$ & 4 & 5 & 1 & - & - & 10 \\
\hline $\begin{array}{l}\text { If I were an inspector, I would } \\
\text { like to use it. }\end{array}$ & 5 & 5 & - & - & - & 10 \\
\hline $\begin{array}{l}\text { I believe the expert inspectors } \\
\text { would like to use it. }\end{array}$ & 3 & 6 & 1 & - & - & 10 \\
\hline \multicolumn{7}{|l|}{ Ease of Learning } \\
\hline I learned to use it quickly. & 5 & 5 & - & - & - & 10 \\
\hline $\begin{array}{l}\text { I find it easy to remember } \\
\text { how to use it. }\end{array}$ & 7 & 3 & - & - & - & 10 \\
\hline Learning how to use it is easy. & 7 & 3 & - & - & - & 10 \\
\hline I quickly became skilful with it. & 2 & 8 & - & - & - & 10 \\
\hline \multicolumn{7}{|l|}{ Satisfaction and Pleasure } \\
\hline I am satisfied with it. & 1 & 9 & - & - & - & 10 \\
\hline It is fun to use it. & 6 & 4 & - & - & - & 10 \\
\hline $\begin{array}{l}\text { It works the way I expect and } \\
\text { I want it to work. }\end{array}$ & 1 & 7 & 2 & - & - & 10 \\
\hline It is functional. & 3 & 7 & - & - & - & 10 \\
\hline $\begin{array}{l}\text { I want to have it if I become } \\
\text { an expressway inspector. }\end{array}$ & 3 & 7 & - & - & - & 10 \\
\hline I find it pleasant to use. & 2 & 7 & 1 & - & - & 10 \\
\hline
\end{tabular}

\section{Results from the Refined Version of the HoloSpector Application}

\section{Participants' demographic information}

There were three male EXAT inspectors for the testing of the refined version of the application. For the second test of the refined version, one engineer was 32 years old, the other engineer was 34 years old and the technician was 33 years old. Both engineers hold a bachelor's degree and the technician holds an engineering diploma qualification in construction. The age of the participants was later found to have no influence on the testing results of the Holospector application.

\section{Test durations}

It took an average of $58 \mathrm{~min}$ for the EXAT inspectors to complete the assessment. One engineer took $57 \mathrm{~min}$, the other took $60 \mathrm{~min}$, while the technician took $56 \mathrm{~min}$. Compared to the preliminary version, the test duration of the refined 
version was longer due to the more comprehensive nature of the assessment and the functionality of the application. In other words, EXAT inspectors needed to test more functions in the refined version. In contrast, the postgraduate students tested only the basic functions in the preliminary version.

\section{Assessment of the refined version of the HoloSpector application}

Prior to testing the refined version of the application, all EXAT inspectors had not yet known about AR technology. They had never experienced AR applications or any wearable devices and they were all first-timers in using and testing the Microsoft HoloLens. Figure 9 shows the testing of the refined version by EXAT inspectors in the onsite inspections of elevated expressway structures. Table 2 shows the results of the 5-point Likert questions on certain factors. These factors were perceived ease of use, perceived usefulness, ease of learning, attitude towards use, behavioural intention to use, satisfaction and pleasure, comfort of the wearable HoloLens and evaluation of the refined version of the Holospector application. Specific findings from these questions are highlighted as follows:

1. Perceived ease of use: Two EXAT inspectors agreed and the other was neutral with the acceptable loading time and effortlessness of this version. They all agreed with the terminology used and easiness of this version. One inspector strongly agreed, another inspector agreed and the other inspector was neutral with the user-friendliness of this version.

2. Perceived usefulness: All three EXAT inspectors agreed with the usefulness of using this application in their job to improve data communication and management of expressway inspections.

3. Ease of learning: All three EXAT inspectors agreed that they learned to use it quickly; it was easy to remember and use and they quickly became skilful with it.

4. Attitude towards use: All three EXAT inspectors agreed that they liked and looked forward to using the Holospector application for expressway inspections.

5. Behavioural intention to use: One EXAT inspector strongly agreed and the other two agreed that they intended to use it in the future.

6. Satisfaction and pleasure: All three EXAT inspectors agreed that they were satisfied with it and using it was fun and pleasant. Two inspectors agreed and the other inspector was neutral that it worked the way they expected and wanted it to work and that it was functional.

7. Comfort of the wearable HoloLens: One inspector agreed, one inspector was neutral and the other inspector disagreed with the comfort of the wearable HoloLens.

8. Evaluation of the refined version: Two of the three EXAT inspectors estimated and believed that the application would save $2 \mathrm{~h}$ compared to paper-based approaches. Two inspectors agreed and the other inspector was neutral with the following: The buttons were well-designed and easy- 
to-click, the augmented real-world contents made sense, the sequences of the application's features could be easily understood. They and other expressway inspectors would like to use it. Two inspectors agreed and the other inspector disagreed with the menu screen and layout. They all agreed with the improvement of data communication and management and data accuracy. One inspector strongly agreed, another inspector agreed and the other inspector was neutral with the money savings. One inspector strongly agreed and the other two inspectors agreed with the right amount of information in this wearable AR system.
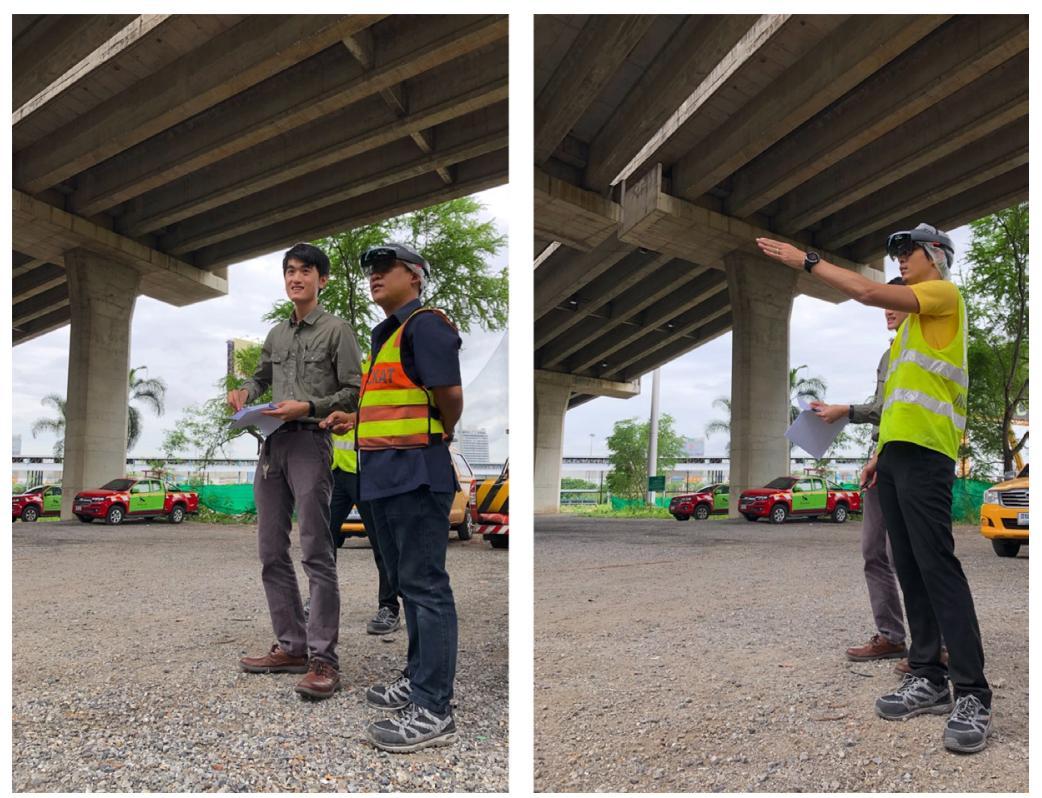

Figure 9. EXAT inspectors wearing Microsoft HoloLens and testing the refined version of the Holospector application onsite

Table 2. Summary of results of 5-point Likert questions on the usability and acceptability of the refined version of the HoloSpector application

\begin{tabular}{lcccccc}
\hline 5-Point Likert Questions & $\begin{array}{c}\text { Strongly } \\
\text { Agree }\end{array}$ & Agree & Neutral & $\begin{array}{c}\text { Disagree } \\
\begin{array}{l}\text { Strongly } \\
\text { Disagree }\end{array}\end{array}$ & Total \\
\hline $\begin{array}{l}\text { Perceived Ease of Use } \\
\begin{array}{l}\text { The loading time of the } \\
\text { application is acceptable. }\end{array}\end{array}$ & - & 2 & 1 & - & - & 3 \\
$\begin{array}{l}\text { The words used in the } \\
\text { application are simple } \\
\text { and easily understood. }\end{array}$ & - & 3 & - & - & - & 3 \\
It is simple and easy to use. & - & 3 & - & - & - & 3 \\
\hline
\end{tabular}


Table 2. Continued

\begin{tabular}{|c|c|c|c|c|c|c|}
\hline 5-Point Likert Questions & $\begin{array}{l}\text { Strongly } \\
\text { Agree }\end{array}$ & Agree & Neutral & Disagree & $\begin{array}{l}\text { Strongly } \\
\text { Disagree }\end{array}$ & Total \\
\hline It is user-friendly. & 1 & 1 & 1 & - & - & 3 \\
\hline $\begin{array}{l}\text { It is effortless and I can use it } \\
\text { without written instructions. }\end{array}$ & - & 2 & 1 & - & - & 3 \\
\hline \multicolumn{7}{|l|}{ Perceived Usefulness } \\
\hline $\begin{array}{l}\text { Compared to the current } \\
\text { approach, using Holospector } \\
\text { in an expressway inspection } \\
\text { is useful because it would } \\
\text { improve data communication } \\
\text { and management. }\end{array}$ & - & 3 & - & - & - & 3 \\
\hline $\begin{array}{l}\text { I would find HoloSpector } \\
\text { useful in my job. }\end{array}$ & - & 3 & - & - & - & 3 \\
\hline \multicolumn{7}{|l|}{ Ease of Learning } \\
\hline I learned to use it quickly. & - & 3 & - & - & - & 3 \\
\hline $\begin{array}{l}\text { I find it easy to remember and } \\
\text { easy to learn how to use it. }\end{array}$ & - & 3 & - & - & - & 3 \\
\hline I quickly became skilful with it. & - & 3 & - & - & - & 3 \\
\hline \multicolumn{7}{|l|}{ Attitude Towards Use } \\
\hline $\begin{array}{l}\text { I look forward to those aspects } \\
\text { of my job that require the use } \\
\text { of the HoloSpector application. }\end{array}$ & - & 3 & - & - & - & 3 \\
\hline $\begin{array}{l}\text { I like working with the } \\
\text { Holospector application. }\end{array}$ & - & 3 & - & - & - & 3 \\
\hline \multicolumn{7}{|l|}{ Behavioural Intention to Use } \\
\hline $\begin{array}{l}\text { I intend to continue to use } \\
\text { the HoloSpector application } \\
\text { in the future. }\end{array}$ & 1 & 2 & - & - & - & 3 \\
\hline \multicolumn{7}{|l|}{ Satisfaction and Pleasure } \\
\hline I am really satisfied with it. & - & 3 & - & - & - & 3 \\
\hline It is fun and pleasant to use it. & - & 3 & - & - & - & 3 \\
\hline $\begin{array}{l}\text { It works the way I expect } \\
\text { and I want it to work. }\end{array}$ & - & 2 & 1 & - & - & 3 \\
\hline It is functional. & - & 2 & 1 & - & - & 3 \\
\hline \multicolumn{7}{|l|}{ Comfort of the Wearable HoloLens } \\
\hline $\begin{array}{l}\text { I feel comfortable when } \\
\text { wearing the Microsoft } \\
\text { HoloLens. }\end{array}$ & - & 1 & 1 & 1 & 0 & 3 \\
\hline
\end{tabular}


Table 2. Continued

\begin{tabular}{|c|c|c|c|c|c|c|}
\hline 5-Point Likert Questions & $\begin{array}{l}\text { Strongly } \\
\text { Agree }\end{array}$ & Agree & Neutral & Disagree & $\begin{array}{l}\text { Strongly } \\
\text { Disagree }\end{array}$ & Total \\
\hline \multicolumn{7}{|c|}{ Evaluation of the Refined Version of the HoloSpector Application } \\
\hline $\begin{array}{l}\text { The buttons are well-designed } \\
\text { and easy-to-click. }\end{array}$ & - & 2 & 1 & - & - & 3 \\
\hline $\begin{array}{l}\text { The menu screen and layout } \\
\text { are clear and well-designed. }\end{array}$ & - & 2 & - & 1 & - & 3 \\
\hline $\begin{array}{l}\text { This application improves } \\
\text { the expressway inspection } \\
\text { data communication and } \\
\text { management (data } \\
\text { collection, data storage } \\
\text { and data transfer). }\end{array}$ & - & 3 & - & - & - & 3 \\
\hline $\begin{array}{l}\text { This application would } \\
\text { improve the data accuracy } \\
\text { (reduce errors) in expressway } \\
\text { inspections. }\end{array}$ & - & 3 & - & - & - & 3 \\
\hline $\begin{array}{l}\text { This application would save } \\
\text { time in expressway inspections. }\end{array}$ & - & 1 & 2 & - & - & 3 \\
\hline $\begin{array}{l}\text { This application would } \\
\text { save money in expressway } \\
\text { inspections. }\end{array}$ & 1 & 1 & 1 & - & - & 3 \\
\hline $\begin{array}{l}\text { This application provides } \\
\text { me with the right amount } \\
\text { of information needed in } \\
\text { an expressway inspection. }\end{array}$ & 1 & 2 & - & - & - & 3 \\
\hline $\begin{array}{l}\text { The contents augmented } \\
\text { on Microsoft HoloLens in } \\
\text { the real world make sense } \\
\text { in the context I use it. }\end{array}$ & - & 2 & 1 & - & - & 3 \\
\hline $\begin{array}{l}\text { I can easily understand } \\
\text { the sequences of using the } \\
\text { HoloSpector application on } \\
\text { Microsoft HoloLens. }\end{array}$ & - & 2 & 1 & - & - & 3 \\
\hline $\begin{array}{l}\text { As an EXAT expressway } \\
\text { inspector, I would like to use it. }\end{array}$ & - & 2 & 1 & - & - & 3 \\
\hline $\begin{array}{l}\text { I believe other expressway } \\
\text { inspectors would also like } \\
\text { to use it. }\end{array}$ & - & 2 & 1 & - & - & 3 \\
\hline
\end{tabular}




\section{Discussion}

\section{Discussion of the test results of the preliminary version of the HoloSpector application}

It was found that only eight out of the 10 participants had heard about $A R$ technology and used certain AR mobile applications; however, none of them had ever used the Microsoft HoloLens. This means that a wearable AR system was still new for them since they all answered in the questionnaire that it was their first time in using the Microsoft HoloLens. The results of research conducted by Radkowski and Ingebrand (2017) revealed that all HoloLens users give positive feedback. Users strongly agree that they find it enjoyable in utilising and experiencing the Microsoft HoloLens. Most users also find it comfortable to wear.

In summary, the research results showed that the UI of the wearable AR system was simple, acceptable and well-designed. All participants were positive towards the Holospector application. They all accepted that the application was practical, easy to learn and use, satisfactory and pleasant. However, there were two main challenges faced by the participants. One participant found the application a bit slow. Another participant reported that the Microsoft HoloLens caused eye strain and neck pain after long use. Furthermore, some participants suggested that the application needed to work faster and that the holographic menu needed to be scaled down to fit in the field of view (FoV) of the Microsoft HoloLens. More significantly, some participants thought that AR technology was very useful, necessary and sophisticated for infrastructure inspection, particularly for expressway inspections. In connection with AR technology, some participants could see the benefits of using the Microsoft HoloLens in this field. Most importantly, all participants agreed with the use of the HoloSpector application of the wearable AR system in expressway inspections. They thought that it was well-developed, would reduce errors, time and labour and would speed up the on-site inspection activities.

\section{Discussion of the test results of the refined version of the Holospector application}

All EXAT engineers and the technician had not yet known about AR technology and had never experienced any AR applications or wearable devices, including the Microsoft HoloLens. Similar to the postgraduate students, they were all firsttimers in using the Microsoft HoloLens. In summary, the research results obtained from the final test demonstrated certain achievements and improvements of the Holospector application, as discussed as follows:

1. In the contexts of EXAT's onsite inspections of expressway structures, they all accepted that it was user-friendly, practical, functional, easy to learn and use, useful, satisfactory and pleasant.

2. Regarding time savings, they believed that using the refined version of the Holospector application for expressway inspections would save $2 \mathrm{~h}$ compared to the EXAT's current approach which is a paper-based and manual approach. 
3. To some extent, they could see that this AR-based approach would help save resources such as the workforce (fewer EXAT inspectors going to the site) and material use (cameras and paper). For instance, they expected that only one inspector or one engineer would be enough for an onsite inspection. They are now going to the site as a group of two individuals. Besides, 40 pages of A4 paper would not be used anymore.

4. More significantly, this AR-based approach was believed to increase their work productivity; they expected that they would be able to extend onsite inspections of expressway structures from $2 \mathrm{~km}$ to $4 \mathrm{~km}$.

5. Since time and resources were saved and work productivity was increased, the costs of onsite inspections would decrease.

6. They could also see improvements in data communication and management (data, collection, data storage and data transfer) between the site and office. The developed wearable AR system would also help ensure data accuracy.

7. This final test gives a clear direction (adding a few more inspection functions) for the next version of the Holospector application, in which all inspection forms for expressway inspections by EXAT need to be included.

\section{Research contributions and potential benefits for EXAT}

This exploratory study helped establish a baseline understanding of EXAT's current practices of expressway inspections in Thailand, which used paper-based forms. Innovative digitalisation approaches to improve the effectiveness and efficiency are still required. This finding resulted in the design and development of the Holospector application that was created specifically for EXAT's inspection activities. From the results of the assessment, it was generally agreed by the two groups of users that the Holospector application could be an innovative and digital approach for EXAT to employ in expressway inspection activities in Thailand in the near future. More significantly, it could help digitalise and improve the EXAT's current data communication and management; the wearable AR system is able to send and store the collected inspection data in the online database in real-time. The collected inspection data can also be accessed and shared in real-time. Most significantly, it could allow the users to access the inspection history, expressway technical drawings, expressway specifications, expressway manuals, etc. from the online database in real-time.

For EXAT's current onsite inspections of expressway structures, the refined version of the Holospector application provided five following potential benefits as described:

1. Hands-free onsite inspection of expressway structures: EXAT inspectors could use this wearable AR system to perform onsite inspection operations in a hands-free manner. With the use of the Microsoft HoloLens, a fullyuntethered wearable device, they could launch the Holospector application to fulfil the inspection tasks. These tasks include holographically viewing technical drawings, manuals, history, or specifications of expressway structures and digitally collecting and automatically sending 
the inspection data to the online database in real-time. In other words, they can freely walk and inspect the expressway structures without holding and wearing additional sensors, a head tracker and a mounted computer besides the Microsoft HoloLens.

2. Improved data communication and management with online database: The conventional approach (known as a manual or paper-based approach) could be transformed into a digital AR approach. By using the application, the expressway inspectors can select the pre-populated data (name, direction, locations, damage types, condition ratings and comments) in the application. The inspectors can then click the submit button to send the selected data to the online database in real-time (e.g. Google spreadsheet) where everyone can access, edit and share with other relevant individuals. The developed wearable AR system simplifies and helps onsite inspectors to perform inspection tasks in a new and digital manner. As a result, the inspection tasks can be done onsite. This AR-based approach also helped to improve data accuracy, compared to a handwriting or paper-based approach.

3. Resource savings: The refined version of the Holospector application in EXAT's expressway inspections would help save resources including inspection tools (cameras), material use (paper) and workforce (EXAT engineers and technicians). Microsoft HoloLens is capable of capturing photos and videos; therefore, cameras might not be needed. However, their quality and resolution are lower than cameras but still acceptable. The EXAT's current approach uses a lot of A4 paper (40 sheets per day) to collect the onsite inspection data. Onsite inspectors need to manually write down the data on paper, so using the refined version of the Holospector application would be more environmentally friendly and save paper for other uses. The EXAT engineers believed that this digital AR approach would also reduce the workforce from four persons (current EXAT teams) to two persons for one inspection. They believed that they could perform the inspection tasks more independently onsite.

4. Increased work productivity: The developed AR-based approach for expressway inspections would increase the work productivity from $2 \mathrm{~km}$ to $4 \mathrm{~km}$ according to EXAT engineers. This approach could help EXAT teams to finish an inspection cycle (onsite inspection and data input at the office) onsite; hence, this reduces the time of data input in the EXAT office and they could use this saved time to double onsite inspections.

5. Time and cost savings: The current inspection cycle from an onsite inspection to data input at the office takes approximately $4.5 \mathrm{~h}$ (3 h for an onsite inspection by two engineers and two technicians and $1.5 \mathrm{~h}$ for data input by one data entry clerk); however, it was revealed that using the developed digital AR approach for an onsite inspection of expressway structures would save $2 \mathrm{~h}$ according to the EXAT inspectors and only two engineers would be needed. This digital approach helps EXAT teams to send and automatically store the collected data in the online database; thus, it saves another $1.5 \mathrm{~h}$ for data input and does not require a data entry clerk. It can be concluded that the digital approach saves 
$3.5 \mathrm{~h}$ for the daily inspection cycle of a $2-\mathrm{km}$ inspection of expressway structures. Most significantly, the saved time could be converted to cost savings in the daily inspection cycle. The hourly salary of an engineer, a technician and a data entry clerk is approximately THB 187.5, THB143.75 and THB50, respectively. The current daily inspection cycle of a 2-km inspection of expressway structures would cost THB2,062.5 while using the developed digital approach would cost only THB375. Therefore, it would save THB1,687.5 daily for a $2-\mathrm{km}$ inspection, which saves $81.82 \%$. One unit of the first-generation Microsoft HoloLens costs USD3,000. The cost savings of onsite inspections could be invested in purchasing the device. About THB1,678.5 (approximately USD56.25) would be saved per 2-km inspection cycle; in other words, USD900 would be saved monthly (16 working days). It could be concluded that one unit of Microsoft HoloLens could be purchased in around 3.5 months (i.e., the pay-back period, assuming one 2-km inspection cycle per working day).

\section{CONCLUSION AND FUTURE WORK}

This study illustrated that the developed Holospector application was satisfactory, easy to use and learn, useful, user-friendly and practical for expressway inspections. All participants showed their positive feelings and preferences for the developed wearable AR system (the preliminary and the refined version of the Holospector application and Microsoft HoloLens). They also believed that this would be a new, digital, innovative and feasible approach for the EXAT to apply in onsite inspections of expressway structures in Thailand. During the inspection activities, the wearable AR system allows an onsite inspector to perform hands-free inspection tasks. It does this by superimposing the relevant information, namely, expressway history, technical drawings, previous inspection reports or history and manuals of specification and standards for expressways onto the real scene while an inspector is viewing an expressway. This study benefits and helps AR developers to enhance their AR prototypes or applications based on the design considerations, development and the results discussed above.

Many directions could be considered for future work. The results obtained from this research illustrated positive and good results in general. The next version of the Holospector application should be developed and equipped with complete functionality as discussed below and a full set of all EXAT inspection forms. The refined version of the Holospector application was designed and developed for one form, "RA1 Routine Inspection Form for Chalerm Maha Nakorn Expressway (Concrete Structure) Superstructure", out of the 15 forms of "Routine Inspection" of the EXAT. All forms for "Routine Inspection" and "Daily Inspection" can be included. There are a total of 33 forms.

The functionality of the refined version should be developed and equipped with a few more functions, namely: (1) A photo or video function allowing onsite inspectors to capture photos or videos (inside the developed application), with specific locations of damage, which would be very helpful in aiding the actual classification of damage or making repair recommendations, (2) A function to locate the damaged structures and (3) A function to remember the structures that 
have not been inspected and map out the unfinished structures or locations. In addition, a marker-based approach should be integrated into the application to allow the onsite inspectors to retrieve the information of expressway structures.

The research presented in this article should be interpreted, considering the following limitations:

1. Sample size: There were 10 postgraduate students and three EXAT inspectors that participated in this research and their responses were subjective; therefore, the number of participants should be enlarged to increase the confidence and accuracy of the results. In other words, the larger the sample size is, the more accurate the results are. In this regard, time and availability could be the two main constraints for an increase in sample size.

2. Functionality improvement of the Holospector application: The three functions mentioned above should be developed and marker-based AR should also be considered in the development of the Holospector application.

3. Testing of the refined version on different sites: The refined version of the Holospector application should be tested on a few more sites, to investigate the issues and challenges of the developed wearable AR system in different environments for onsite inspections of expressway structures.

4. Other limitations include those associated with the Microsoft HoloLens itself. For example, narrow FoV, lighting restrictions in bright lights, comfort, weight distribution, cost and difficulties of data input. For onsite inspections, safety helmets are required for protecting the inspectors from fatal head injuries. It was found that the first generation of Microsoft HoloLens could not be worn with the current safety-helmet type used by the EXAT. Specially designed helmets fitted with the Microsoft HoloLens for EXAT teams are therefore required. Microsoft has collaborated with Trimble to produce an American National Standards Institute (ANSI)approved HoloLens hard-hat solution with an embedded HoloLens device called "Trimble's HoloLens hard hat" for those who work in construction environments. Such a solution can be considered by the EXAT in the future.

Future development of the application might benefit from incorporating other international infrastructure maintenance frameworks or standards (such as those from the American Society of Civil Engineers, ASCE) to further enhance the application.

\section{ACKNOWLEDGEMENTS}

This research was supported by the SIIT Young Researcher Grant (No. SIIT 2017-YRG-KP01) provided by Sirindhorn International Institute of Technology, Thammasat University and the Chair Professor Grant (P-19-52302) provided by the National Science and Technology Development Agency (NSTDA), 
Thailand. The first author is also grateful to ASEAN University Network/Southeast Asia Engineering Education Development Network (AUN-SEED/Net) for the scholarship support.

\section{REFERENCES}

Ammari, K.E. and Hammad, A. (2014). Collaborative BIM-based markerless mixed reality framework for facilities maintenance. In R.I. Issa and I. Flood (eds.), Computing in Civil and Building Engineering (2014). Reston, VA: American Society of Civil Engineers (ASCE). https://doi.org/10.1061/9780784413616.082.

Azuma, R.T. (1997). A survey of augmented reality. Presence: Teleoperators and Virtual Environments, 6(4): 355-385. https://doi.org/10.1162/pres.1997.6.4 .355 .

Bademosi, F., Blinn, N. and Issa, R.R.A. (2019). Use of augmented reality technology to enhance comprehension of construction assemblies. Journal of Information Technology in Construction (ITcon), 24: 58-79.

Bernard, M.L., Chaparro, B.S., Mills, M.M. and Halcomb, C.G. (2003). Comparing the effects of text size and format on the readibility of computer-displayed Times New Roman and Arial text. International Journal of HumanComputer Studies, 59(6): 823-835. https://doi.org/10.1016/S1071-5819(03) 00121-6.

Blankemeyer, S., Wiemann, R. and Raatz, A. (2018). Intuitive assembly support system using augmented reality. In T. Schüppstuhl, K. Tracht and J. Franke (eds.), Tagungsband des 3. Kongresses Montage Handhabung Industrieroboter. Berlin: Springer Vieweg. https://doi.org/10.1007/978-3-662 -56714-2_22.

Canepa-Talamas, D., Nassehi, A. and Dhokia, V. (2017). Innovative framework for immersive metrology. Procedia CIRP, 60: 110-115. https://doi.org/10 .1016/j.procir.2017.02.028.

Chalhoub, J. and Ayer, S.K. (2019). Effect of varying task attributes on augmented reality aided point layout. Journal of Information Technology in Construction (ITcon), 24: 95-111.

Chen, W., Li, C.T. and Cheng, J.C. (2019). A BIM-based location aware AR collaborative framework for facility maintenance management. Journal of Information Technology in Construction (ITcon), 24: 360-380.

Eschen, H., Kötter, T., Rodeck, R., Harnisch, M. and Schüppstuhl, T. (2018). Augmented and virtual reality for inspection and maintenance processes in the aviation industry. Procedia Manufacturing, 19: 156-163. https://doi.org/ 10.1016/j.promfg.2018.01.022.

Fishbein, M. and Ajzen, I. (1975). Belief, Attitude, Intention and Behavior: An Introduction to Theory and Research. Reading, MA: Addison-Wesley.

Guhl, J., Vick, A., Vonasek, V. and Krüger, J. (2018). Visualizing trajectories for industrial robots from sampling-based path planning on mobile devices. In T. Schüppstuhl, K. Tracht and J. Franke (eds.), Tagungsband des 3. Kongresses Montage Handhabung Industrieroboter. Berlin: Springer Vieweg. https://doi.org/10.1007/978-3-662-56714-2_6. 
Hammad, A., Garrett, J., James, H. and Karimi, H.A. (2004). Location-based computing for infrastructure field tasks. In H.A. Karimi and A. Hammad (eds.), Telegeoinformatics: Location-based Computing and Services. Boca Raton, FL: CRC Press, 287-314.

. (2002). Potential of mobile augmented reality for infrastructure field tasks. In K.C.P. Wang, S. Madanat, S. Nambisan and G. Spring (eds.), Applications of Advanced Technologies in Transportation (2002). Reston, VA: ASCE. https://doi.org/10.1061/40632(245)54.

Hanson, R., Falkenström, W. and Miettinen, M. (2017). Augmented reality as a means of conveying picking information in kit preparation for mixedmodel assembly. Computers and Industrial Engineering, 113: 570-575. https://doi.org/10.1016/j.cie.2017.09.048.

Hou, L. and Wang, X. (2013). A study on the benefits of augmented reality in retaining working memory in assembly tasks: A focus on differences in gender. Automation in Construction, 32: 38-45. https://doi.org/10.1016/ j.autcon.2012.12.007.

Kalantari, M. and Rauschnabel, P. (2018). Exploring the early adopters of augmented reality smart glasses: The case of Microsoft HoloLens. In T. Jung and M. tom Dieck (eds.), Augmented Reality and Virtual Reality. Cham, Switzerland: Springer. https://doi.org/10.1007/978-3-319-64027-3_16.

Karlsson, I., Bernedixen, J., Ng, A.H. and Pehrsson, L. (2017). Combining augmented reality and simulation-based optimization for decision support in manufacturing. In 2017 Winter Simulation Conference (WSC), 2017. Piscataway, NJ: Institute of Electrical and Electronics Engineers (IEEE), 3988-3999. https://doi.org/10.1109/WSC.2017.8248108.

Koch, C., Neges, M., König, M. and Abramovici, M. (2014). Natural markers for augmented reality-based indoor navigation and facility maintenance. Automation in Construction, 48: 18-30. https://doi.org/10.1016/j.autcon .2014.08.009.

Kooper, R. and Maclntyre, B. (2003). Browsing the real-world wide web: Maintaining awareness of virtual information in an AR information space. International Journal of Human-Computer Interaction, 16(3): 425--446. https://doi.org/ 10.1207/S15327590IJHC1603_3.

. (2001). An interface for a continuously available, general purpose, spatialized information space. Paper presented at the $\mathrm{HCl}$ International 2001. New Orleans, Los Angeles, 5-10 August.

Kopsida, M. and Brilakis, I. (2016). BIM registration methods for mobile augmented reality-based inspection. In S. Christodoulou and R. Scherer (eds.), eWork and eBusiness in Architecture, Engineering and Construction: ECPPM 2016: Proceedings of the 11th European Conference on Product and Process Modelling (ECPPM 2016), Limassol, Cyprus, 7-9 September 2016. Boca Raton, FL: CRC Press, 201.

Lang, S., Kota, M.S.S.D., Weigert, D. and Behrendt, F. (2019). Mixed reality in production and logistics: Discussing the application potentials of Microsoft HoloLens ${ }^{\mathrm{TM}}$. Procedia Computer Science, 149: 118-129. https://doi.org/ 10.1016/j.procs.2019.01.115.

Meža, S., Turk, Ž. and Dolenc, M. (2014). Component based engineering of a mobile BIM-based augmented reality system. Automation in Construction, 42: 1-12. https://doi.org/10.1016/j.autcon.2014.02.011. 
Parkes, A. (2013). The effect of task-individual-technology fit on user attitude and performance: An experimental investigation. Decision Support Systems, 54(2): 997-1009. https://doi.org/10.1016/j.dss.2012.10.025.

Radkowski, R. and Ingebrand, J. (2017). HoloLens for assembly assistance: A focus group report. In S. Lackey and J. Chen (eds.), Virtual, Augmented and Mixed Reality. VAMR 2017. Lecture Notes in Computer Science, Vol. 10280. Cham, Switzerland: Springer, 274-282. https://doi.org/10.1007/978-3-319 -57987-0_22.

Rückert, P., Meiners, F. and Tracht, K. (2018). Augmented reality for teaching collaborative robots based on a physical simulation. In T. Schüppstuhl, K. Tracht and J. Franke (eds.), Tagungsband des 3. Kongresses Montage Handhabung Industrieroboter. Berlin: Springer Vieweg. https://doi.org/10 .1007/978-3-662-56714-2_5.

Suksuwan, N. and Hadikusumo, B.H. (2010). Condition rating system for Thailand's concrete bridges. Journal of Construction in Developing Countries, 15(1): $1-27$.

Taylor, A.G. (2016). Develop Microsoft HoloLens Apps Now. Berkeley, CA: Apress. https://doi.org/10.1007/978-1-4842-2202-7.

Venkatesh, V., Thong, J.Y. and $X \cup, X$. (2012). Consumer acceptance and use of information technology: Extending the unified theory of acceptance and use of technology. MIS Quarterly, 36(1): 157-178. https://doi.org/10.2307/ 41410412.

Wang, J., Wang, X., Shou, W. and XU, B. (2014). Integrating BIM and augmented reality for interactive architectural visualisation. Construction Innovation, 14(4): 453-476. https://doi.org/10.1108/Cl-03-2014-0019.

Wang, X., Kim, M.J., Love, P.E. and Kang, S.-C. (2013a). Augmented reality in built environment: Classification and implications for future research. Automation in Construction, 32: 1-13. https://doi.org/10.1016/j.autcon.2012 .11 .021 .

Wang, X., Love, P.E., Kim, M.J., Park, C.-S., Sing, C.-P. and Hou, L. (2013b). A conceptual framework for integrating building information modeling with augmented reality. Automation in Construction, 34: 37-44. https://doi .org/10.1016/j.autcon.2012.10.012.

Webster, A., Feiner, S., Maclntyre, B., Massie, W. and Krueger, T. (1996). Augmented reality in architectural construction, inspection and renovation. In J. Vanegas and P. Chinowsky (eds.), Computing in Civil Engineering: Proceedings of the Third Congress Held in Conjunction with A/E/C Systems '96, Anaheim, California, June 17-19, 1996. Reston, VA: ASCE, 913-919. 